\title{
Traceability: Perception and attitudes of artisanal cheese producers in Brazil
}

\author{
Beatriz O. Pelegrino, ${ }^{1}$ Ramon Silva,,${ }^{1,2}$ Jonas T. Guimarães, ${ }^{1}$ Nathalia F. Coutinho, ${ }^{1}$ Tatiana C. Pimentel, ${ }^{3}$ \\ Bruna G. Castro, ${ }^{4}$ Mônica Q. Freitas, ${ }^{1}$ Erick A. Esmerino, ${ }^{1}$ Anderson S. Sant'Ana, ${ }^{4}$ Márcia C. Silva, ${ }^{2}$ \\ Denise R. A. Perdomo, ${ }^{2}$ Maximiliano S. Pinto, ${ }^{5}$ Maria Carmela H. K. Duarte, ${ }^{1}$ and Adriano G. Cruz ${ }^{2 *}$ \\ ${ }^{1}$ Faculdade de Medicina Veterinária, Universidade Federal Fluminense (UFF), 24230-340 Niterói, Brazil \\ ${ }^{2}$ Departamento de Alimentos, Instituto Federal de Educação, Ciência e Tecnologia do Rio de Janeiro (IFRJ), 20270-021, Rio de Janeiro, Brazil \\ ${ }^{3}$ Instituto Federal do Paraná (IFPR), Paranavaí 87703-536, Paraná, Brazil \\ ${ }^{4}$ Faculdade de Engenharia de Alimentos (FEA), Departamento de Ciência de Alimentos, Universidade Estadual de Campinas (UNICAMP), \\ 13083-862, Campinas, São Paulo, Brazil \\ ${ }^{5}$ Departamento de Engenharia de Alimentos, Universidade Federal de Minas Gerais (UFMG), Montes Claros, Minas Gerais 39403-215, Brazil
}

\begin{abstract}
This study aimed to evaluate the perceptions and attitudes of artisanal cheese producers $(\mathrm{n}=40)$ in Brazil regarding the implementation of traceability. A questionnaire consisting of 16 statements using a 5-point Likert scale was applied, and descriptive statistics and factor analysis were used for data analysis. The implementation of a traceability system can reduce the number of consumer complaints and the loss of products, in addition to increasing supplier control and process safety, thus protecting health and increasing consumer confidence. However, we did not find consensus on the relationship between implementation of a traceability system and rapid recalls in crisis episodes, or on the reduction in recalls and their negative impact on consumers. Because of the costs that drive implementation of this technology, some artisanal cheese producers do not consider a traceability system as a current reality to monitor their production. We concluded that Brazilian artisanal cheese producers have limited awareness of the impact of traceability implementation, which restricts investments in the system.

Key words: food production, food safety, quality control, questionnaire survey, artisanal cheese
\end{abstract}

\section{INTRODUCTION}

Artisanal cheeses are typically characterized by small-scale production using farm-produced raw milk and traditional manufacturing techniques (RamírezRivera et al., 2018). Artisanal cheese in Brazil has great social importance due to its contribution to the income of small family farmers (Kamimura et al., 2019a; Ro-

Received December 1, 2019.

Accepted January 23, 2020.

*Corresponding author: food@globo.com drigues et al., 2020). Minas Gerais is considered the largest cheese-producing state in Brazil, with approximately $25 \%$ of the country's production originating there and 27,000 small and medium-sized producers living in 519,823 municipalities of Minas Gerais (Correia and Assis, 2017; Abras Brasil, 2019). Brazilian artisanal cheeses differ from industrialized cheeses in their processing, type of milk used, ripening time (if ripened), characteristics (texture, size, shape, color, and flavor), moisture content, and use of starter cultures or not, among others (Kamimura et al., 2019a). In addition, the hygienic-sanitary factor can affect product quality (Kamimura et al., 2019b) and a recurring problem for small and medium-scale producers of artisanal cheeses is a deficiency in good manufacturing and handling practices and application of food safety tools, which usually leads to product contamination (Andretta et al., 2019; Aragão et al., 2019).

The increased consumer demand for reliable foods, changes in eating habits and lifestyle, as well as increased consumer incomes and health awareness have motivated producers and industries to implement traceability systems (Bosona and Gebresenbet, 2013). According to Charlebois and Haratifar (2015), traceability is "the ability to trace products back and forth throughout the supply chain, from farm or point of production to the end user." Traceability systems also aim to remove foods that may pose a public health risk from the production chain as quickly as possible (Maldonado-Siman et al., 2013). According to the Codex Alimentarius (WHO/FAO, 2009), food safety is defined as "the assurance that food will not cause harm to the consumer when it is prepared and/or eaten according to its intended use." Therefore, traceability can be a food safety tool, reducing the chance of people consuming deteriorated or contaminated foods, because they can be withdrawn from circulation by food recall actions. In addition, traceability implementation can improve supply management, enable product certifica- 
tion and accreditation, protect brands, reduce distribution costs, and increase consumer confidence in the product (Dandage et al., 2017; Crovato et al., 2019). However, traceability systems must offer benefits that outweigh implementation and operation costs. Often, the associated costs and benefits are not considered by producers and industries, making it difficult to implement these systems (Maldonado-Siman et al., 2013). Briefly, perception is how people understand presented information, whereas attitude is the willingness to act or react in a particular way; therefore, perceptions and attitudes about traceability may be different among different types of food producers.

Traceability plays a key role in food chain management, especially in the case of highly perishable and rapidly deteriorating foods such as milk and dairy products (Mania et al., 2018). Few studies have been published on the traceability of food products and are generally related to meat (fish and red meat; Forås et al., 2015) and fruits and vegetables (Dandage et al., 2017); studies related to milk and dairy products remain scarce (Maldonado-Siman et al., 2013; Fåras et al., 2015). Despite the existence of a few studies evaluating consumer perceptions about traceability (Charlebois and Haratifar, 2015; Matzembacher et al., 2018), only one study has focused on the dairy producers' point of view (Lopes et al., 2020) but it did not evaluate artisanal cheese producers. In this sense, we aimed to evaluate the perception and attitudes of Brazilian producers of artisanal cheese about the implementation of traceability systems.

\section{MATERIALS AND METHODS}

Forty artisanal cheese producers $(n=40)$ in Minas Gerais State, Brazil, participated in this study from April to October 2019. Face-to-face interviews were conducted on different artisanal cheese-producing farms.

To assess the perception and attitudes of artisanal cheese producers of the traceability system, a questionnaire (Table 1) consisting of 16 statements (Maldonado-Siman et al., 2013; Mattevi and Jones, 2016) was developed using a 5 -point Likert scale ( $1=$ strongly disagree, $3=$ neither agree nor disagree, $5=$ strongly agree; Pacheco et al., 2018). The statements were prepared according to the reality of artisanal cheese production in Brazil and considered the importance of traceability systems and their effects on the dairy production chain as well as the issue involving food safety.

Descriptive statistics (mean and standard deviation) and factor analysis were used to analyze the results. Principal component analysis was used as the Varimax extraction and rotation method for greater separation of items. Factors with eigenvalues $>1$ were considered relevant. Factor analysis data were examined for normality, collinearity, and outlier distribution, by KaiserMeyer-Olkin (KMO) test, Cronbach's a coefficient, and Bartlett's test for sphericity, and used to determine the confidence level and the suitability of using the factor analysis (Pacheco et al., 2018). All analyses were performed using XLSTAT 2019.2 software (Addinsoft, Paris, France).

Table 1. Mean (SD) scores of the statements concerning the perceptions and attitudes of Brazilian artisanal cheese producers toward traceability ${ }^{1}$

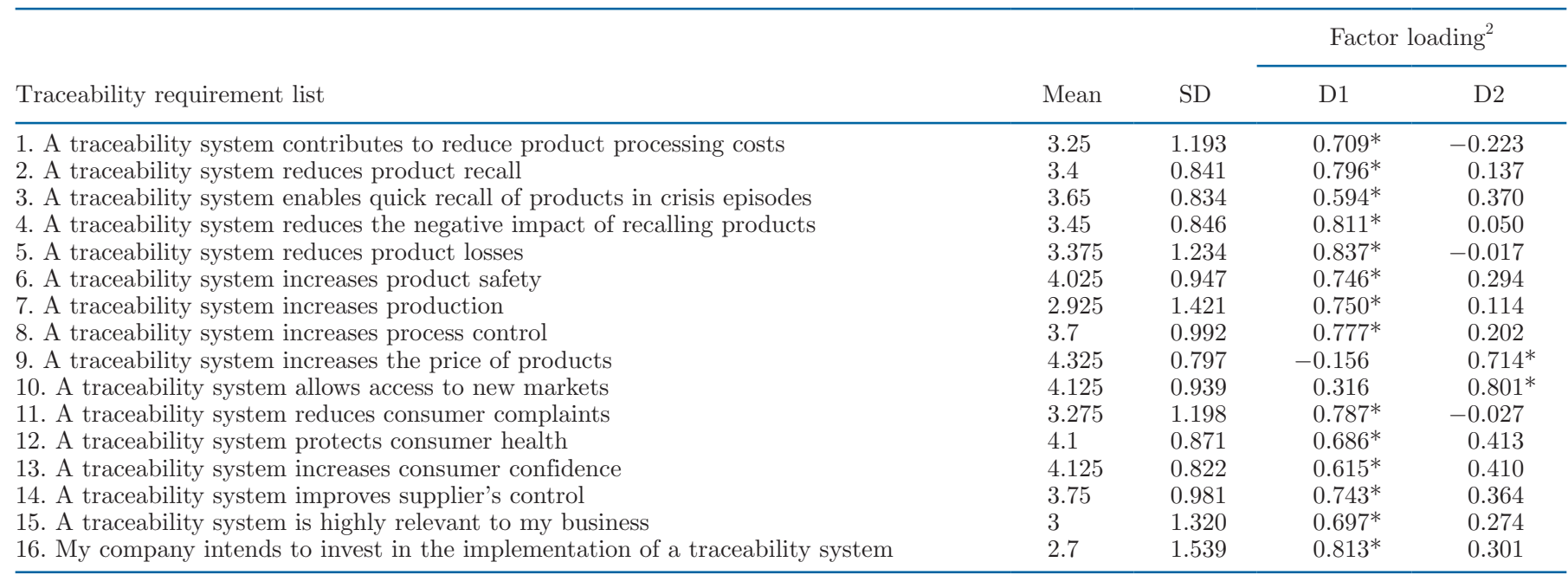

${ }^{1}$ Results are expressed as mean (SD) in accordance with the Likert scale: 1 = strongly disagree; $2=$ slightly disagree; $3=$ neither agree nor disagree; $4=$ slightly agree; $5=$ strongly agree.

${ }^{2} \mathrm{D} 1, \mathrm{D} 2$ = first and second dimensions of the factorial analysis.

*Factor loadings are significant in the axis after Varimax rotation. 
- Strongly disagree $\square$ Slightly disagree $\square$ Neither agree nor disagree $\square$ Slightly agree $\square$ Strongly agree

1. A traceability system contributes to reduce product processing costs

2. A traceability system reduces product recall

3. A traceability system enables quick recall of products in crisis episodes

4. A traceability system reduces the negative impact of recalling products

5. A traceability system reduces product losses

6. A traceability system increases product safety

7. A traceability system increases production

8. A traceability system increases process control

9. A traceability system increases the price of products

10. A traceability system allows access to new markets

11. A traceability system reduces consumer complaints

12. A traceability system protects consumer health

13. A traceability system increases consumer confidence

14. A traceability system improves suppliers control

15. A traceability system is highly relevant to my business.

16. My company intends to invest in the implementation of a traceability system.

\section{$0 \%$}

$10 \%$

$20 \%$

$30 \%$

$40 \%$

$50 \%$

$60 \%$

$70 \%$

\section{RESULTS AND DISCUSSION}

Figure 1 shows the percentage of responses of artisanal cheese producers for each item of the questionnaire concerning the Likert scale, and Table 1 presents the mean scores, standard deviations, and factor loadings of the statements evaluated in the first 2 dimensions of factor analysis.

Factor analysis explained $62.50 \%$, corresponding to 49.14 and $13.36 \%$ in the first (D1) and second (D2) dimensions, respectively. The moderate percentage of explanation suggests a moderate knowledge about the traceability systems. Cronbach's $\alpha$ was used to determine the reliability of the scale, and the value (0.934) indicated that the scale can be considered of high consistency; values $>0.6$ are considered good (Maciel et al., 2013). Two tests can be applied to the factor analysis to assess the adequacy of the scale: the KMO measure of sample adequacy and Bartlett's sphericity test. The $\mathrm{KMO}$ indicates the correlation between the variables, and the closer the correlation is to +1 , the stronger the correlation (Santos et al., 2019). Pacheco et al. (2018) reported that KMO values $>0.5$ are considered adequate. In the present study, KMO was 0.799 , indicating good correlation between the variables.

Bartlett's sphericity test was significant $(P<0.01)$, confirming the relationship between the variables. A statistically significant Bartlett test $(P<0.05)$ indicates that sufficient correlations exist between variables to perform the analysis (Sobhanifard, 2018; Santos et al., 2019). In the commonality analysis, a value $<0.3$ suggests a weak relationship between variables (Rahnama et al., 2017; Sobhanifard, 2018). All 16 items on the Likert scale were important for the attitudes of artisanal cheese producers toward a traceability system (commonalities from 0.55 to 0.8 ), indicating moderate to strong correlations between the variables.

The first dimension (D1) positively correlated with the statements 1 to 8 and 11 to 16 (Table 1 ) corresponding to cost reduction, the occurrence of a recall, the negative impact of a recall, product losses, and consumer complaints. In addition, D1 was related to increased production, supplier control, product safety, consumer health protection, and consumer confidence. Finally, a positive correlation was observed between the relevance of the traceability system and investment for implementation. The second dimension (D2) correlated positively with statements 9 and 10, related to the increase in product prices and access to new markets.

Artisanal cheese producers agreed that implementation of a traceability system enables rapid recall of products, thereby reducing the number of consumer complaints and product losses; $47.5,40$, and $45 \%$ of producers responded that they agree slightly or extremely 
(scores 4 and 5 on the Likert scale, Figure 1) with statements 3,11 , and 5, respectively. However, 67.5, 50, and $70 \%$ of respondents neither agreed nor disagreed with statements 2, 3, and 4 (Figure 1), indicating that they are not sure if traceability systems allow a quick recall in crisis episodes and the negative impact of recalls on consumer behavior. Thus, the results indicate that artisanal cheese producers do not have sufficient technical knowledge about the objectives of traceability systems and their advantages, which is to quickly remove from circulation foods that may pose a risk to public health. The more accurate a traceability system is, the faster that product safety and quality problems can be identified (Golan et al., 2004). Product recall, as well as other types of negative publicity, can severely damage a company's image, with a resulting impact on consumer confidence (Zhao et al., 2013). This result may be associated with the profile of cheese producers in the country because artisanal cheeses are produced on a small scale by farmers, who often have low education levels.

For artisanal cheese producers, implementing a traceability system can result in increased process and supplier control and greater process safety, protecting consumer health and increasing consumer confidence. Overall, 50, 45, 67.5, 72.5, and $77.5 \%$ of respondents reported that they agree slightly or extremely (scores 4 and 5, Figure 1) with the statements 8, 14, 6, 12, and 13 (Table 1), respectively. Traceability can guarantee the quality of production and products, which increases food safety and protection and maintains consumer confidence (Maldonado-Siman et al., 2013; Dandage et al., 2017). From a consumer perspective, traceability strengthens consumer confidence and its relationship with the producer, whereas for the producer, it is part of an economic involvement that can assist in improving and reducing impacts on food safety, as well as the effective recovery of improper products through recall events (Aung and Chang, 2014). Traceability also contributes to food fraud prevention and tampering (Dandage et al., 2017). According to Li et al. (2019), consumers of dairy products prefer to purchase products from companies with traceability systems because they have greater confidence in the products. Therefore, for artisanal cheese producers, traceability is strongly associated with process and product safety and consumer protection. Some experts have argued that safety is the most important component of quality because poor safety can result in serious injury and even consumer death (Aung and Chang, 2014).

Artisanal cheese producers agreed that the implementation of a traceability system can reduce process costs, but it increases the price of the product; 50 and $80 \%$ of respondents reported that they agree slightly or extremely (scores 4 and 5, Figure 1) with statements 1 and 9, respectively. This result demonstrates an important knowledge of cheese producers about the costs involved with implementation of a traceability system, because these systems can decrease product recall and product operation, storage, and distribution costs (Dandage et al., 2017). However, it is worth noting that there is an implementation cost, including equipment purchases, labor, system management, and traceability efficiency testing (Golan et al., 2004), which can result in products in the market with less competitive prices (Maldonado-Siman et al., 2013).

There was no consensus among artisanal cheese producers about the relationship between the implementation of traceability systems and increased production; $37.5 \%$ of respondents reported that they agree slightly or extremely (scores 4 and 5) with statement 7 , whereas $45 \%$ disagreed slightly or extremely (scores 1 and 2 ). Although implementation of a traceability system results in qualitative and quantitative improvements in the food supply, storage, inventory, and production (Aung and Chang, 2014), this information is still to be fully understood by the artisanal cheese producers.

The relationship between traceability and access to new markets was considered important by $67.5 \%$ of the artisanal cheese producers, who slightly or extremely agreed with statement 10 (scores 4 and 5, Table 1). According to Brazilian legislation, traceability must be assured at all stages of the production chain to ensure effective collection (Brazil Ministério da Saúde, 2015). In addition, several countries have passed mandatory traceability regulations in recent years, and products can only be imported from companies that have traceability systems in place (Dandage et al., 2017). Therefore, Brazilian artisanal cheese producers are aware that implementation of traceability systems is important for the global marketing of their products.

There was no consensus among the artisanal cheese producers about the relevance and intention of investing in traceability systems; 33 and $32.5 \%$ of respondents answered that they agree slightly or extremely (scores 4 and 5) with statements 15 and 16, whereas 40.5 and $45 \%$ disagreed slightly or extremely (scores 1 and 2 ). This result suggests that small producers do not have sufficient technical knowledge to meet the challenge of implementing a traceability system, thus they have no intention of investing in the system at this time. One of the factors that may have contributed to this result is the current economic situation in Brazil, and traceability is not considered a priority for the producers under study. Moreover, our results correlate with the fact that producers understand that implementation of traceability systems increases the price of products. Some researchers have reported that the cost associated 
with implementing traceability systems is seen as a barrier to supply chain actors, especially small producers in less developed countries (Aung and Chang, 2014).

Disinterest and lack of technological knowledge hamper the implementation of traceability in the sector of artisanal cheese production in Brazil. Wu et al. (2015) observed, in their study of Chinese consumers of pork products, that education, age, and income were important factors affecting knowledge of traceability and influencing the willingness to pay for these products. For example, younger consumers ( $<35$ yr old) had a greater ability to accept and understand traceability information, and they understood how traceability processes can effectively prevent safety risks. In the same study, quality certification was the most important characteristic influencing the consumer preferences, followed by appearance and traceability information. Another study evaluating the preference and the willingness to pay for food traceability using a choice experiment with Fuji apples in China (Liu et al., 2019) indicated that people's valuations for traceable food can differ depending on the degree of trust in their government's supervision of food safety and food labels.

Overall, traceability is not yet a well-known system among producers and consumers, depending on several factors, which must be evaluated to achieve efficient traceability implementations, increase consumer satisfaction, reduce implementation costs, and improve the financial return (Stranieri et al., 2017; Haleem et al., 2019). Some strategies to improve the rate of traceability system implementation among artisanal cheese producers might include creating "trust seals" that add value to a product and increase its sales, creating products with a target audience interested in traceability information, improving technology transfer to small and medium-scale producers, and investing in advertisements explaining the importance of traceability to consumers.

\section{CONCLUSIONS}

Brazilian artisanal cheese producers have heterogeneous perceptions of traceability; however, what they have in common is limited knowledge about the importance of traceability systems and associations of this quality tool with food safety, which may result in the protection of consumer health and an increase in consumer confidence. However, we did not find consensus on the relationship between implementation of a traceability system and rapid recalls in crisis episodes, or on the reduction in recalls and their negative impact on consumers. The observed attitude of many producers, characterized by small and medium-sized farmers, was not to invest in implementation of traceability, because they consider that it would increase the price of the product. Further studies focused on the implementation of traceability systems for these products should be conducted to encourage the use of this tool to monitor and control products and processes, because it ensures food safety and consumers' confidence.

\section{ACKNOWLEDGMENTS}

This study was financed in part by the Coordenação de Aperfeiçoamento de Pessoal de Nível Superior-Brasil (CAPES; Finance Code 001), Fundação de Amparo a Apoio a Pesquisa no Rio de Janeiro (FAPERJ), and Instituto Federal de Educação, Ciência e Tecnologia (IFRJ; Brazil). A. S. Sant'Ana and A. G. Cruz are grateful to Conselho Nacional de Desenvolvimento Científico e Tecnológico (CNPq, grant nos. 302763/2014-7 and \#305804/2017-0). The authors declare that they have no conflicts of interest.

\section{REFERENCES}

Abras Brasil. 2019. Com 25\% da produção nacional, MG aposta no queijo como saída para crise e geração de renda. Accessed Nov. 27, 2019. http://www.abras.com.br/clipping.php?area=1\&clipping= 67836.

Andretta, M., T. T. Almeida, L. R. Ferreira, A. F. Carvalho, R. S. Yamatogi, and L. A. Nero. 2019. Microbial safety status of Serro artisanal cheese produced in Brazil. J. Dairy Sci. 102:10790-10798. https://doi.org/10.3168/jds.2019-16967.

Aragão, B. B., S. C. Trajano, J. G. Silva, B. P. Silva, R. P. Oliveira, J. W. Pinheiro Junior, R. M. Peixoto, and R. A. Mota. 2019. High frequency of $\beta$-lactam-resistant Staphylococcus aureus in artisanal coalho cheese made from goat milk produced in northeastern Brazil. J. Dairy Sci. 102:6923-6927. https://doi.org/10.3168/jds.2018 $-16162$.

Aung, M. M., and Y. S. Chang. 2014. Traceability in a food supply chain: Safety and quality perspectives. Food Control 39:172-184. https://doi.org/10.1016/j.foodcont.2013.11.007.

Bosona, T., and G. Gebresenbet. 2013. Food traceability as an integral part of logistics management in food and agricultural supply chain. Food Control 33:32-48. https://doi.org/10.1016/j.foodcont .2013.02.004.

Brazil Ministério da Saúde. 2015. RDC N² 24, de 08 de junho de 2015. Dispõe sobre o recolhimento de alimentos e sua comunicação à Anvisa e aos consumidores. Brazil Ministério da Saúde/Agência Nacional de Vigilância Sanitária. Accessed Nov. 27, 2019. www anvisa.gov.br.

Charlebois, S., and S. Haratifar. 2015. The perceived value of dairy product traceability in modern society: An exploratory study. J. Dairy Sci. 98:3514-3525. https://doi.org/10.3168/jds.2014-9247.

Correia, V. T. V., and I. C. L. Assis. 2017. Queijos artesanais: Revisão de literatura. Nutritime 14:8001-8008. [In Portuguese]

Crovato, S., G. Mascarello, S. Marcolin, A. Pinto, and L. Ravarotto. 2019. From purchase to consumption of bivalve molluscs: A qualitative study on consumers' practices and risk perceptions. Food Control 96:410-420. https://doi.org/10.1016/j.foodcont.2018.09 .040 .

Dandage, K., R. Badia-Melis, and L. Ruiz-García. 2017. Indian perspective in food traceability: A review. Food Control 71:217-227. https://doi.org/10.1016/j.foodcont.2016.07.005.

Forås, E., M. Thakur, K. Solem, and R. Svarva. 2015. State of traceability in the Norwegian food sectors. Food Control 57:65-69. https://doi.org/10.1016/j.foodcont.2015.03.027. 
Golan, E. H., B. Krissoff, F. Kuchler, L. Calvin, K. E. Nelson, and G. K. Price. 2004. Traceability in the US food supply: Economic theory and industry studies. Agricultural Economic Report No. (AER-830). USAD Economic Research Service, Washington, DC. https://www.ers.usda.gov/publications/pub-details/?pubid= 41632.

Haleem, A., S. Khan, and M. I. Khan. 2019. Traceability implementation in food supply chain: A grey-DEMATEL approach. Inf. Process. Agric. 6:335-348. https://doi.org/10.1016/j.inpa.2019.01.003.

Kamimura, B. A., F. De Filippis, A. S. Sant'Ana, and D. Ercolini. 2019b. Large-scale mapping of microbial diversity in artisanal Brazilian cheeses. Food Microbiol. 80:40-49. https://doi.org/10.1016/ j.fm.2018.12.014.

Kamimura, B. A., M. Magnani, W. A. Luciano, F. B. Campagnollo, T. C. Pimentel, V. O. Alvarenga, B. O. Pelegrino, A. G. Cruz, and A. S. Sant'Ana. 2019a. Brazilian artisanal cheeses: An overview of their characteristics, main types and regulatory aspects. Compr. Rev. Food Sci. Food Saf. 18:1636-1657. https://doi.org/10.1111/ 1541-4337.12486.

Li, S., S. J. Sijtsema, M. Kornelis, Y. Liu, and S. Li. 2019. Consumer confidence in the safety of milk and infant milk formula in China. J. Dairy Sci. 102:8807-8818. https://doi.org/10.3168/jds .2019-16638.

Liu, R., Z. Gao, R. M. Nayga Jr., H. A. Snell, and H. Ma. 2019. Consumers' valuation for food traceability in China: Does trust matter? Food Policy 88:101768. https://doi.org/10.1016/j.foodpol .2019.101768.

Lopes, L. O., R. Silva, J. T. Guimarães, N. M. Coutinho, T. C. Pimentel, M. C. K. H. Duarte, M. Q. Freitas, M. C. Silva, E. A. Esmerino, D. R. P. Azeredo, and A. G. Cruz. 2020. Traceability: Perceptions and attitudes of Brazilian non-bovine dairy processors. Food Control 111:107060. https://doi.org/10.1016/j.foodcont .2019.107060.

Maciel, E. D. S., L. K. Savay-da-Silva, J. S. Vasconcelos, J. A. Galvão, J. G. Sonati, D. D. Silva, and M. Oetterer. 2013. Application of exploratory factor analysis to assess fish consumption in a university community. Food Sci. Technol. (Campinas) 33:99-106. https:/ /doi.org/10.1590/S0101-20612013005000016.

Maldonado-Siman, E. M. A., C. S. Godinez-Gonzalez, J. A. CadenaMeneses, A. Ruíz-Flores, and G. Aranda-Osorio. 2013. Traceability in the Mexican dairy processing industry. J. Food Process. Preserv. 37:399-404. https://doi.org/10.1111/j.1745-4549.2011 .00663.x.

Mania, I., A. M. Delgado, C. Barone, and S. Parisi. 2018. Traceability in the Dairy Industry in Europe. Springer International Publishing, Heidelberg, Germany.

Mattevi, M., and J. A. Jones. 2016. Traceability in the food supply chain: Awareness and attitudes of UK small and medium-sized enterprises. Food Control 64:120-127. https://doi.org/10.1016/j foodcont.2015.12.014.
Matzembacher, D. E., I. D. Carmo Stangherlin, L. A. Slongo, and R. Cataldi. 2018. An integration of traceability elements and their impact in consumer's trust. Food Control 92:420-429. https://doi .org/10.1016/j.foodcont.2018.05.014.

Pacheco, M. H., S. P. Kuriya, C. S. Capobiango, T. C. Pimentel, A. G. Cruz, E. A. Esmerino, and M. Q. Freitas. 2018. Exploration of gender differences in bottled mineral water consumption: A projective study of consumer's perception in Brazil. J. Sens. Stud. 33:e12434. https://doi.org/10.1111/joss.12434.

Rahnama, H., M. Fadaei, and S. Baghersalimi. 2017. Healthy food choice: Survey results from Iranian consumers toward antibioticfree chicken. J. Sens. Stud. 32:e12248. https://doi.org/10.1111/ joss.12248.

Rodrigues, J. F., B. A. Mangia, J. G. e Silva, G. A. Lacorte, L. O. Coimbra, E. A. Esmerino, M. Q. Freitas, A. C. M. Pinheiro, and A. G. Cruz. 2020. Sorting task as a tool to elucidate the sensory patterns of artisanal cheeses. J. Sens. Stud. https://doi.org/10 .1111 joss. 12562.

Ramírez-Rivera, E. de J., P. Díaz-Rivera, L. G. Ramón-Canul, J. M. Juárez-Barrientos, J. Rodríguez-Miranda, E. Herman-Lara, W. Prinyawiwatkul, and J. A. Herrera-Corredor. 2018. Comparison of performance and quantitative descriptive analysis sensory profiling and its relationship to consumer liking between the artisanal cheese producers panel and the descriptive trained panel. J. Dairy Sci. 101:5851-5864. https://doi.org/10.3168/jds.2017-14213.

Santos, T. D. C., M. D. S. Rodrigues, L. P. D. França, B. K. Ceratti, and P. P. M. Meneses. 2019. Construção de uma Escala de Clima Organizacional para uma Organização Pública. Rev. Psico. Org. Trabalho 19:713-719. https://doi.org/10.17652/rpot/2019.3 .16709.

Sobhanifard, Y. 2018. Hybrid modelling of the consumption of organic foods in Iran using exploratory factor analysis and an artificial neural network. Br. Food J. 120:44-58. https://doi.org/10.1108/ BFJ-12-2016-0604.

Stranieri, S., L. Orsi, and A. Banterle. 2017. Traceability and risks: An extended transaction cost perspective. Supply Chain Manag. 22:145-159. https://doi.org/10.1108/SCM-07-2016-0268.

WHO/FAO. 2009. Codex Alimentarius: Food hygiene, basic texts. Ed. 4. World Health Organization and Food and Agriculture Organization of the United Nations. Accessed February 19, 2020. http:// www.fao.org/3/a1552e/a1552e00.pdf.

Wu, L., S. Wang, D. Zhu, W. Hu, and H. Wang. 2015. Chinese consumers' preferences and willingness to pay for traceable food quality and safety attributes: The case of pork. China Econ. Rev. 35:121-136. https://doi.org/10.1016/j.chieco.2015.07.001.

Zhao, X., Y. Li, and B. B. Flynn. 2013. The financial impact of product recall announcements in China. Int. J. Prod. Econ. 142:115123. https://doi.org/10.1016/j.ijpe.2012.10.018. 